\title{
Influence of different Agrobacterium rhizogenes strains on hairy root induction and analysis of phenolic and flavonoid compounds in marshmallow (Althaea officinalis L.)
}

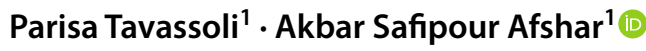

Received: 8 November 2017 / Accepted: 27 July 2018 / Published online: 31 July 2018

(c) Springer-Verlag GmbH Germany, part of Springer Nature 2018

\begin{abstract}
Hairy roots were induced in Althea officinalis using Agrobacterium rhizogenes, strains A4, A13, ATCC15834, and ATCC15834 $(\mathrm{GUS})$. The leaf, petiole and shoot explants of marshmallow were used for the hairy roots induction. When hairy roots appeared, cultures were established in MS (Murashige and Skoog) liquid medium without growth regulators. Hairy roots in explants appeared 5-12 days after inoculation. Maximum transformation frequency of $83 \%$ was observed on shoot explants with ATCC15834 strain. Among the strains, ATCC15834 ${ }_{(\mathrm{GUS})}$ strain showed better potential in the mass production of hairy roots in the hormone-free liquid medium after 50 days of culturing. The highest total phenolic and flavonoids content was found at $1.57 \pm 0.1 \mathrm{mg} / \mathrm{g}$ dry weight in A13 strain and $3.47 \pm 0.3 \mathrm{mg} / \mathrm{g}$ in A4 strain, respectively. Secondary metabolite content of hairy roots was found to be strain-specific.
\end{abstract}

Keywords Agrobacterium rhizogenes $\cdot$ Althaea officinalis $\cdot$ rolB $\cdot$ Secondary metabolites $\cdot$ Transgenic roots

\section{Introduction}

Marshmallow (Althaea officinalis L.), is a medicinal plant of Malvaceae family, from Europe and Western Asia. This plant has been well-known for its healing properties since ancient times. The entire plant possesses antitussive, antiviral, and antimicrobial properties. A. officinalis is a main source of mucilage which is useful for respiratory tract diseases like bronchitis, tracheitis, pertussis, and bronchial asthma (Khidyrova et al. 2012). Its roots and leaves include asparagine, althein, flavonol glycosides, pectin, quercetin and phenolic acid components (Shah et al. 2011; Benbassat et al. 2014).

Plant phenolics and flavonoids have attracted a lot of interest because of powerful biological activity and various applications in medicine (Granato et al. 2018). Several studies have focused on the production, purification and enhancement of these compounds in plants (Pistelli et al. 2010; Guerriero et al. 2018). Moreover, the extraction of

Akbar Safipour Afshar

Asafshar@iau-neyshabur.ac.ir

1 Biology Department, Neyshabur Branch, Islamic Azad University, Neyshabur, Iran phytochemicals from plant tissues is subject to limitations due to the impact of ecological conditions on their growth and yield (Panda et al. 2017).

Recent years, Agrobacterium rhizogenes have been used for hairy roots production, a beneficial approach due to their stable growth and enhanced capability of synthesizing secondary metabolites in hormone-free media (Tian 2015). Further, these transformed roots exhibit the characteristic features such as rapid growth, frequent branching, genetic stability and fast mass production (El-Esawi et al. 2017).

Previous studies revealed that hairy roots induced by different bacterial strains vary in growth, morphology, and production of secondary metabolites (Gupta et al. 2016; Thwe et al. 2016). Therefore, based on plant species, a proper Agrobacterium strain must be selected. Different plasmid harbors by the strains cause differences in virulence and morphology of hairy roots (Thwe et al. 2016). Agropinetype strains are the most virulent or hypervirulent and often used in hairy root culture establishment (Lee et al. 2010). However, to date, there are not many reports on the transformation of $A$. officinalis via different $A$. rhizogenes strains for hairy root induction except one preliminary study (Ionkova 1992) and a study by Drake et al. (2013), wherein anti-HIV microbicide 'cyanovirin-N' production from hairy roots (induced by LBA 9402 strain) was reported. Therefore, in 
the present study, we aimed to induce hairy roots of $A$. officinalis using different strains of $A$. rhizogenes and following screening of the hairy roots for production of higher levels of flavonoids and phenolic compounds.

\section{Materials and methods}

\section{Plant material}

Seeds of A. officinalis were surface sterilized with alcohol $(70 \% \mathrm{v} / \mathrm{v})$ for $30 \mathrm{~s}$ and sodium hypochlorite solution $(60 \%$ $\mathrm{v} / \mathrm{v}$ ) for $2 \mathrm{~min}$ and finally washed with sterilized water for 3 times. Sterile seeds were germinated on MS basal medium (Murashige and Skoog 1962) with $30 \mathrm{~g} / \mathrm{L}$ sucrose and $5 \mathrm{~g} / \mathrm{L}$ agar, the $\mathrm{pH}$ of the medium was adjusted to 5.8 with $1 \mathrm{~N}$ $\mathrm{NaOH}$ or $1 \mathrm{~N} \mathrm{HCl}$ prior to sterilization at $121^{\circ} \mathrm{C}$ for $20 \mathrm{~min}$. The seeds were incubated at $25^{\circ} \mathrm{C}$, a $16 / 8 \mathrm{~h}$ (light/dark) photoperiod in growth chambers.

\section{Bacterial strains and culture conditions}

A. rhizogenes strains A4, A13, ATCC 15834, and ATCC15834 (carrying the GUS gene) were used for infections. A single clone of $A$. rhizogenes was selected and cultured on $25 \mathrm{~mL}$ Luria-Bertani (LB) medium (10 g/L bacto-tryptone, $5 \mathrm{~g} / \mathrm{L}$ bacto-yeast extract, $10 \mathrm{~g} / \mathrm{L} \mathrm{NaCl}$, $\mathrm{pH}=7.0$ ). Bacterial cultures were collected at $5000 \mathrm{rpm}$ for 5 min and resuspended at a cell density $\mathrm{A} 600=0.5$ in MS liquid medium (containing sucrose and $100 \mu \mathrm{M}$ acetosyringone) and were shaken for $1 \mathrm{~h}$ in the rotary shaker before inoculation.

\section{Transformation procedure}

Two different procedures were used for inoculation of explants. In the first method, 8-15-day-old shoots and also leaf and petiole explants of 10-30 days old were inoculated using an insulin syringe. In the second procedure, different seedling parts, including shoot, leaf and petiole were isolated from in vitro grown seedlings and were immersed for about $5 \mathrm{~min}$ in liquid bacterial cultures then blotted on sterile filter paper. All the samples transferred to the MS basal medium supplemented with $30 \%$ sucrose, $0.7 \%$ agar (pH 5.8) for cocultivation. After 2 days of co-culture at $25^{\circ} \mathrm{C}$ in the dark, explants were transferred to MS medium containing cefotaxime antibiotic so as to kill the residual Agrobacterium. In the presence of infection, the cultures were washed with $250 \mathrm{mg} / \mathrm{L}$ of cefotaxime solution, and blot-dried on sterile filter paper then transferred to MS medium supplemented with $30 \%$ sucrose, $0.7 \%$ agar (pH 5.8), and $500 \mathrm{mg} / \mathrm{L}$ of cefotaxime. Cefotaxime concentration was then reduced in subsequent subcultures from 500 to $100 \mathrm{mg} / \mathrm{L}$ and finally, cultures free of $A$. rhizogenes were transferred to MS media plates. After the appearance of hairy roots and to obtain the root lines, single roots were picked off and were cultured on hormone-free MS medium in the dark at $25{ }^{\circ} \mathrm{C}$. After several subcultures on fresh solid medium, the roots were transferred to MS liquid medium containing $30 \mathrm{~g} / \mathrm{L}$ sucrose, kept in a rotary shaker at $80 \mathrm{rpm}$ and $25^{\circ} \mathrm{C}$ in darkness, and subcultured routinely every 2 weeks.

\section{DNA isolation and PCR analysis}

Total genomic DNA was isolated from putative transgenic and control hairy root lines by using the CTAB (hexadecyltrimethyl ammonium bromide) DNA isolation method (Moyo et al. 2008). The DNA samples were then used in PCR analysis for detecting the presence of $\mathrm{rolB}$ gene (780 bp) and GUS gene (320 bp) in transgenic hairy root cultures. The primer set for the rolB gene was: $5^{\prime}$-ATGGAT CCCAAATTGCTATTCCCCACGA- $3^{\prime}$ and 5'-TTAGGC TTCTTTCATTCGGTTTACTGCAGC- $3^{\prime}$ and the primer set for GUS gene was: 5'-GGTGGGAAAGCGCGTTACAAG-3' and 5'-TGGATTCCGGCATAGTTAAA-3' (Rahnama et al. 2008). The PCR reaction was carried out in $20 \mu \mathrm{l}$ volume with $20 \mathrm{ng}(1 \mu \mathrm{l}) \mathrm{DNA}, 100 \mathrm{ng}(1 \mu \mathrm{l})$ of forward and reverse primer; $2 \mu \mathrm{l}(1 \mathrm{mM})$ dNTPs; $0.7 \mu \mathrm{l}(2.5 \mathrm{U})$ Taq DNA polymerase; $2 \mu \mathrm{l} 10 \mathrm{x}$ Reaction Buffer; $1 \mu \mathrm{l}(4 \mathrm{mM}) \mathrm{MgCl}_{2}$, $11.3 \mu 1 \mathrm{H}_{2} \mathrm{O}$. PCR reaction comprised 30 cycles. The amplification cycle for rolB gene consisted of denaturation for $1 \mathrm{~min}$ at $94{ }^{\circ} \mathrm{C}$, primer annealing for $1 \mathrm{~min}$ at $54{ }^{\circ} \mathrm{C}$, and primer extension for $1 \mathrm{~min}$ at $72{ }^{\circ} \mathrm{C}$ and final extension for 10 min at $72^{\circ} \mathrm{C}$. Cycling parameters for GUS gene amplification was similar except that the annealing temperature was $62{ }^{\circ} \mathrm{C}$. PCR products were visualized after electrophoresis on a $1 \%$ agarose gel stained with ethidium bromide under UV irradiation. Plasmid DNA from A. rhizogenes strains was isolated by alkaline lysis method (Green and Sambrook 2012) and used as positive control. The genomic DNA from untransformed A. officinalis root was used as a negative control in PCR analysis.

\section{GUS histochemical assay}

Hairy roots were tested for histochemical GUS expression by soaking in X-Gluc solution (Jefferson 1987). Such that 1-cmlong hairy roots from each individual line were excised and transferred into histochemical assay buffer containing $1.0 \mathrm{M}$ phosphate buffer, $1.0 \mathrm{mM}$ ferricyanide, $10 \%$ Triton X-100, $0.5 \mathrm{mM}$ EDTA and 0.1 M 5-Bromo-4-chloro-3-indolyl- $\beta$ D-glucuronide (X-Gluc). The samples were incubated for $16 \mathrm{~h}$ at $37^{\circ} \mathrm{C}$ in the dark. After staining roots and washing several times in $70 \%$ ethanol, GUS expression exerted as a blue color was visualized in the hairy root lines. 


\section{Determination of total phenolic content}

The total phenolic content was determined as described by Benbassat et al. (2014) using Folin-Ciocalteu reagent. $100 \mathrm{mg}$ samples of hairy roots are grounded in $95 \%$ ethanol and the resulting mixtures were incubated for $24 \mathrm{~h}$ in darkness. Then centrifuged (UNIVERSAL 320, Hettich, Germany) at $6000 \mathrm{rpm}$ for $10 \mathrm{~min}$ and the supernatants were collected. $0.5 \mathrm{~mL}$ of the Folin-Ciocalteu reagent was added to $0.5 \mathrm{~mL}$ of each extract. The solution was mixed well, and after $5 \mathrm{~min}, 1 \mathrm{~mL} 20 \%$ solution of sodium carbonate was added. Then, the solution was again mixed and finally, the volume was diluted to $10 \mathrm{ml}$ with distilled water. The mixtures were kept at room temperature for $2 \mathrm{~h}$ and the absorbance was read at $765 \mathrm{~nm}$ (T80, PG Instruments, UK). The data were expressed as pyrogallol equivalent. All analyses were carried out in triplicate and averaged.

\section{Determination of total flavonoid content}

Total flavonoid content was determined following a method by Park et al. (2008). In a test tube, $4 \mathrm{ml}$ of methanolic extracts, $0.15 \mathrm{ml}$ of $\mathrm{NaNO} 2(0.5 \mathrm{M})$ and $0.15 \mathrm{ml}$ of $\mathrm{AlCl} 3.6 \mathrm{H} 2 \mathrm{O}(0.3 \mathrm{M})$ were mixed. After $5 \mathrm{~min}, 1 \mathrm{ml}$ of $\mathrm{NaOH}(1 \mathrm{M})$ was added. The solution was mixed well and the absorbance was measured at $506 \mathrm{~nm}$. The standard curve for total flavonoids was made using rutin standard solution
(0-100 mg/l) under the same procedure. The total flavonoids were expressed as milligrams of rutin equivalents per $g$ of the dried fraction.

\section{Statistical analysis}

All the experiments were performed in triplicates. The data were analyzed using analysis of variance (ANOVA) with Statistical Analysis System (SAS) Version 9.2 (SAS Institute, Cary, NC). Significant differences using means from triplicate analyses $(p<0.05)$ were determined by Duncan's multiple range test.

\section{Results and discussion}

\section{Hairy roots induction}

Hairy roots in explants inoculated with strains A13 (Fig. 1c)

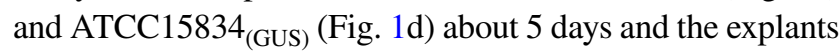
inoculated with strain A4 (Fig. 1a, b) appeared about 12 days after inoculation. Our results showed that roots induced by four A. rhizogenes strains did not differ in morphological characteristics and differed only at the time of appearance. The leaves injured with a sterile scalpel were utilized as the control. Hairy roots were never observed in simply wounded leaves, affirming that development of transformed
Fig. 1 Hairy roots of A. officinalis transformed with different strains of A. rhizogenes 21 days after inoculation (injection by syringe); shoot (a) and leaf explant (b) with A4 strain, leaf explant (c) with A13 strain and petiole explants (d) with ATCC15834 $($ GUS $)$ strain. (a: $2 \times)$ $($ b: $0.6 \times)(\mathbf{c}: 0.3 \times)(\mathbf{d}: 0.5 \times)$
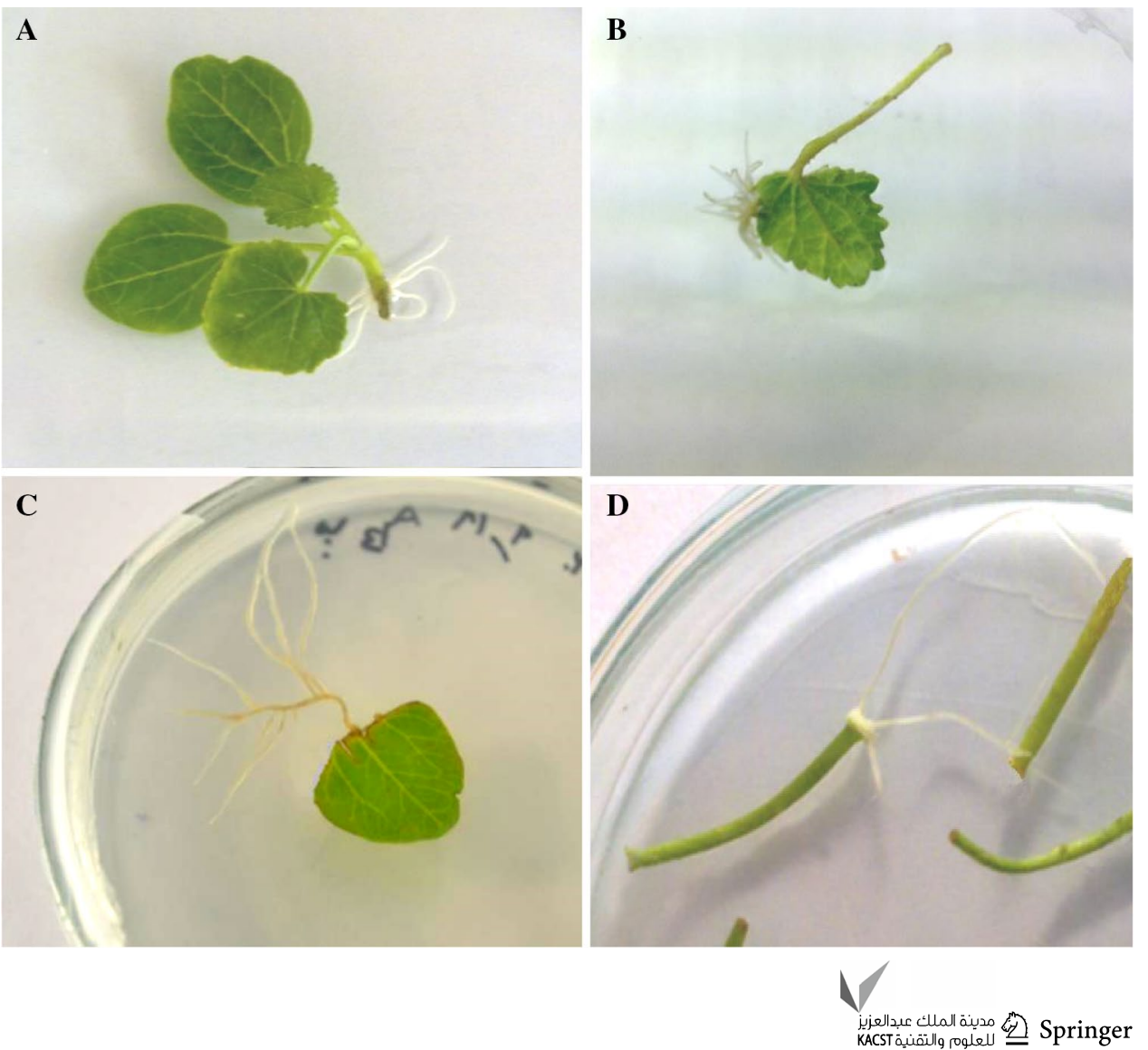
roots came about because of a morphogenetic response not to physiological stresses (Lee et al. 2010).

The efficacy of different bacterial strains in inducing hairy roots in different explants was investigated. The highest transformation frequency was observed by strain ATCC15834 in shoot explant at $83 \pm 5.2 \%$ after 5 days of co-cultivation. Strains A4 and A13 induce rooting in $65 \pm 1.54$ and $45 \pm 2.3 \%$ shoot explants, respectively. In leaf explants of A. officinalis maximum rooting frequency was $60 \pm 6.3 \%$, infected with strain ATCC15834. The induction of hairy roots in petiole explants by ATCC15834, A4 and A13 strains was $76.2 \pm 4.1,60.35 \pm 2.2$ and $55.75 \pm 3.4 \%$, respectively (Fig. 2).

Many factors of plants such as explants type, cultivar, culture conditions and Agrobacterium-host interactions could influence the successful transformation (Colling et al. 2010). Similarly, shoots are the explants of choice for hairy root induction using A. rhizogenes in Artemisia pallens (Pala

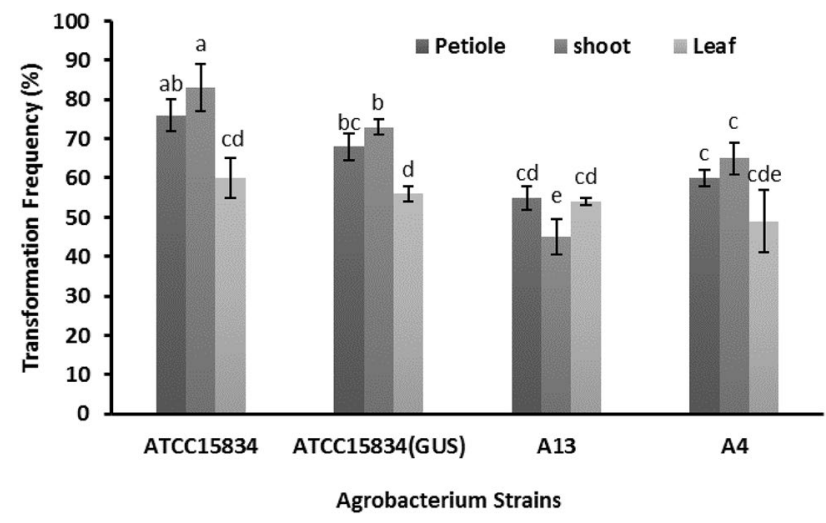

Fig. 2 Comparison of four A. rhizogenes strains and explant type after 5 days of co-cultivation periods on transformation frequency of A. officinalis in the injection method. Bars represent the mean $\pm \mathrm{SD}$ of three independent experiments. Different letters above columns denote statistically significant differences between groups based on the LSD test $(p<0.05)$ et al. 2016), Papaver bracteatum Lindl. (Rostampour et al. 2009) and Dracocephalum moldavica (Weremczuk-Jezyna et al. 2013).

One of the main factors to achieving hairy root induction is the choice of a bacterial strain (Sharifi et al. 2014). Reports on the use of strain ATCC15834 were presented in many plants, including Semecarpus anacardium (Panda et al. 2017), Origanum vulgare (Habibi et al. 2016), Hypericum spp. (Zubricka et al. 2015), Artemisia aucheri (Sharafi et al. 2014) and Nepeta pogonosperma (Valimehr et al. 2014). In most cases, ATCC15834 strain had better performance and proved to be more competent than the others one.

In this study, two methods were used for inoculation explants of marshmallow; direct injection with a syringe and immersion in bacterial suspensions. The majority of shoots and leaf explants were infected by injecting bacteria produced hairy roots (Fig. 1c, d), but in the immersion method, only strain A13 produced hairy roots on leaf explants. Compared to bacteria suspension, insulin syringe provided a lower level of wounded and faced with the less influx of bacteria. Similarly, a study was performed to induce hairy roots of Gentiana scabra, the results showed that stem explants directly injected by A. rhizogenes induced the formation of hairy roots from all inoculated explants and failed to form in control samples (Huang et al. 2014).

On the hormone-free medium isolated roots exhibited a hairy-root phenotype similar to that described: vigorous-rapidly grew, high branching and loss of gravity response. Morphologically transgenic roots (on solid MS medium) revealed no differences in growth and development (Fig. 3a, b) in agreement with Samadi et al. (2014) and Moghadam et al. (2013) studies.

In many plant species, fast growth and high lateral branching are characteristics of transgenic hairy roots resulting from A. rhizogenes (Runo et al. 2012). Integration position and copy number of T-DNA(s) in the plant genome may influence the properties of hairy roots (Tenea et al. 2008). The induction of vir genes in bacteria by signal molecules
Fig. 3 Hairy roots were examined and photographed under a stereomicroscope (SZX2-ILLB, Japan); leaf explant (a) and shoots (b) of marshmallow (a: $6 \times)(b: 8 \times)$
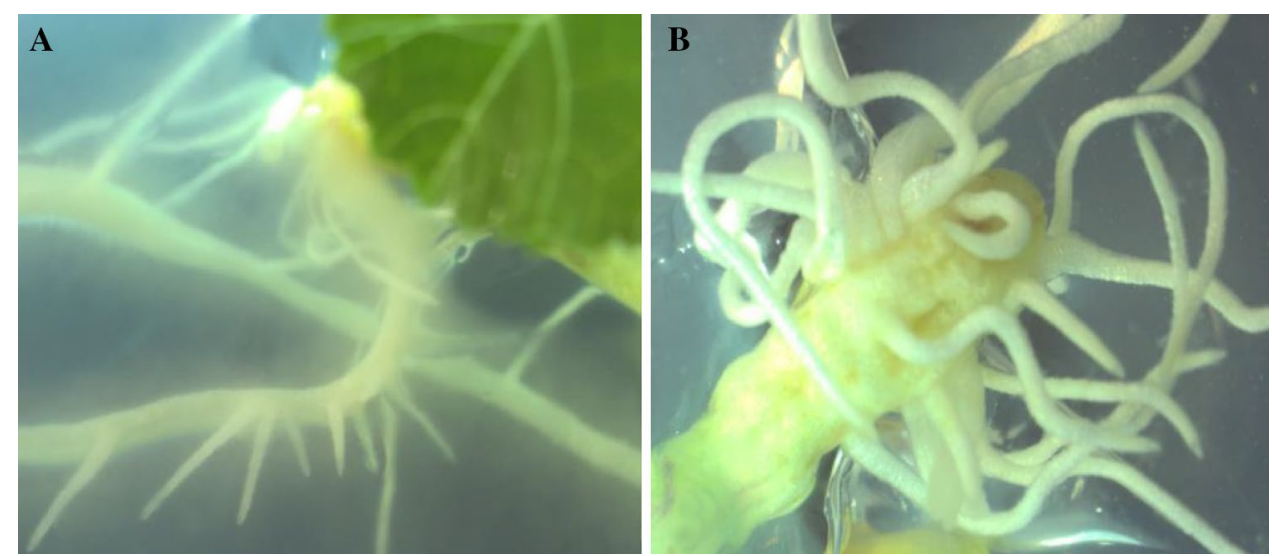
or Agrobacterium Co-cultivation with wounded tissue or media that contains the signal molecules, all these factors would be useful in genetic transformation of some recalcitrant plants (Elfahmi and Chahyadi 2014). Since acetosyringone enhanced Agrobacterium-mediated transformation frequency (Mishra and Ranjan 2008) and reduced the time for induction of hairy roots, so in order to increase the efficiency of gene transfer, it was added to the Agrobacterium suspension medium and co-cultivation medium of explants. Results observed with acetosyringone suggest that this compound is effective to improve genetic transformation in many of species (Nagella et al. 2013).

\section{Establishment of hairy root cultures}

Hairy roots induced by the four strains of $A$. rhizogenes were subcultured to fresh solid MS medium (Fig. 4a) and after sufficient growth hairy roots of A. officinalis were moved to MS liquid medium (Fig. 4b, c).

We observed the rapid growth of hairy roots in the hormone and antibiotic-free liquid MS medium. Particularly, the profuse growth of the hairy roots obtained from ATCC15834 $4_{\text {(GUS) }}$ strain. In other words, hairy roots of strains A4, A13 and ATCC15834 were white, slender, while the transgenic hairy roots of strain ATCC15834 (GUS) were the higher growth rate. These roots are thick and have produced many lateral branches. Furthermore, newly formed hairy roots were white, which later became brown. In agreement with our study, Chandran and Potty (2008) reported that the hairy roots of Ipomoea batatas (two strains, A4 and ATCC15834) were white, slender, branched and brittle; the hairy roots of Canavalia sp. were thick and produced a lot of lateral branches. In another study, hairy roots of Tylophora indica within 3-4 weeks gradually changed from white to yellowish-white, then to reddish-brown within 6-8 weeks (Chaudhuri et al. 2005). It has been reported that the medium type can affect the growth and proliferation of hairy roots and appropriate condition in liquid culture could increase hairy root biomass. Besides, the hairy root cultures formed in liquid medium showed a more rapid growth compared to hairy roots in solid medium (Huang et al. 2014).

\section{Histochemical staining for GUS activity}

Histochemical staining for $\beta$-glucuronidase activity can demonstrate the stable genetic transformation in induced hairy roots. Therefore, the putative transformants were checked for the activity of the reporter gene through GUS assay. In this study, the blue color was observed only in ATCC15834 $($ GUS $)$ transformed roots (Fig. 5a, c, d) whereas control roots (Fig. 5b) did not show GUS activity. These results indicate that the GUS gene in the T-DNA had already been integrated into the genome of the transgenic $A$. officinalis hairy root cultures. Similar results were reported earlier (Liu et al. 2011).

\section{Molecular analysis}

Verification of transgenic nature of the hairy roots was done with PCR amplification of a portion of the rolB gene and a portion of GUS gene. A 780-bp (Fig. 6 left) and 320-bp (Fig. 6 right) fragment amplification were observed in all the hairy root lines. No amplification was detected in negative control as well as in the genomic DNA of non-transformed normal roots (Fig. 6). These results showed the integration of T-DNA (transferred-DNA) into the plant genome and the roots were free of bacteria. The results obtained indicate the same results of $\mathrm{Li}$ et al. (2015) and Moghadam et al. (2013). Among the genes of rol, rolB plays a critical role in pathogenicity, while $\operatorname{rolA}$, rolC and $\operatorname{rolD}$ contribute to the root induction (Sujatha et al. 2013).
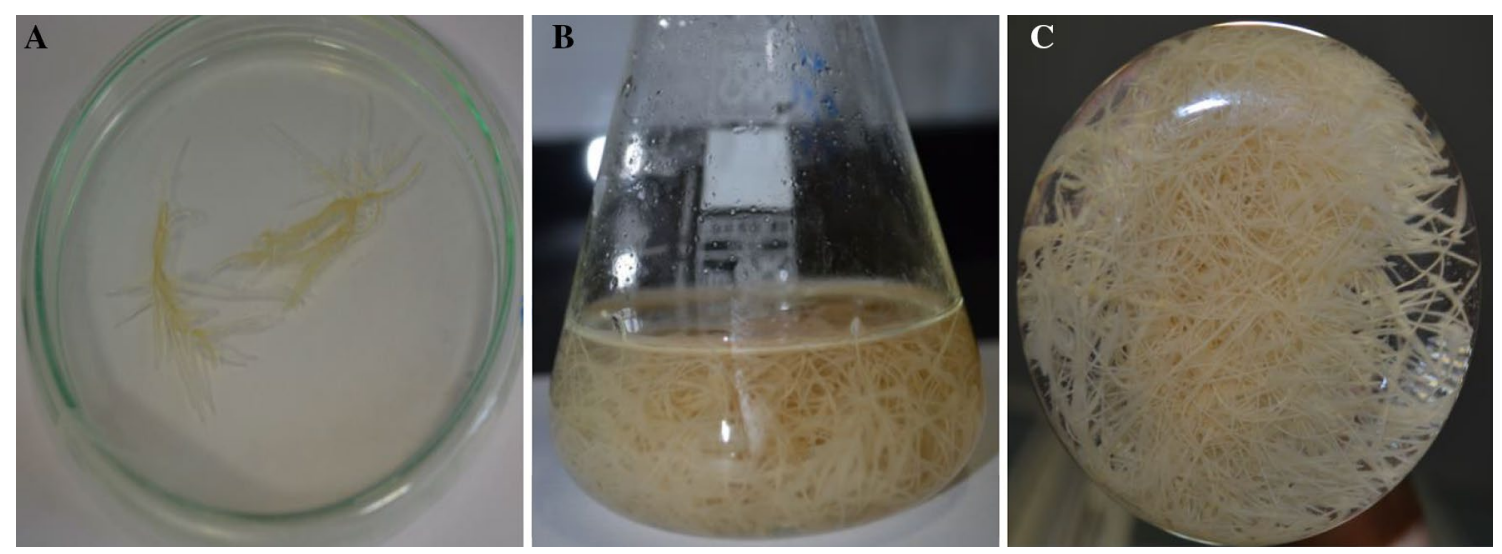

Fig. 4 Rapidly growing hairy roots culture on solid (a) and in liquid (b, c) culture media, in the dark without plant growth regulators (a: $0.3 \times)$ (b: $0.3 \times)(\mathbf{c}: 0.5 \times)$ 


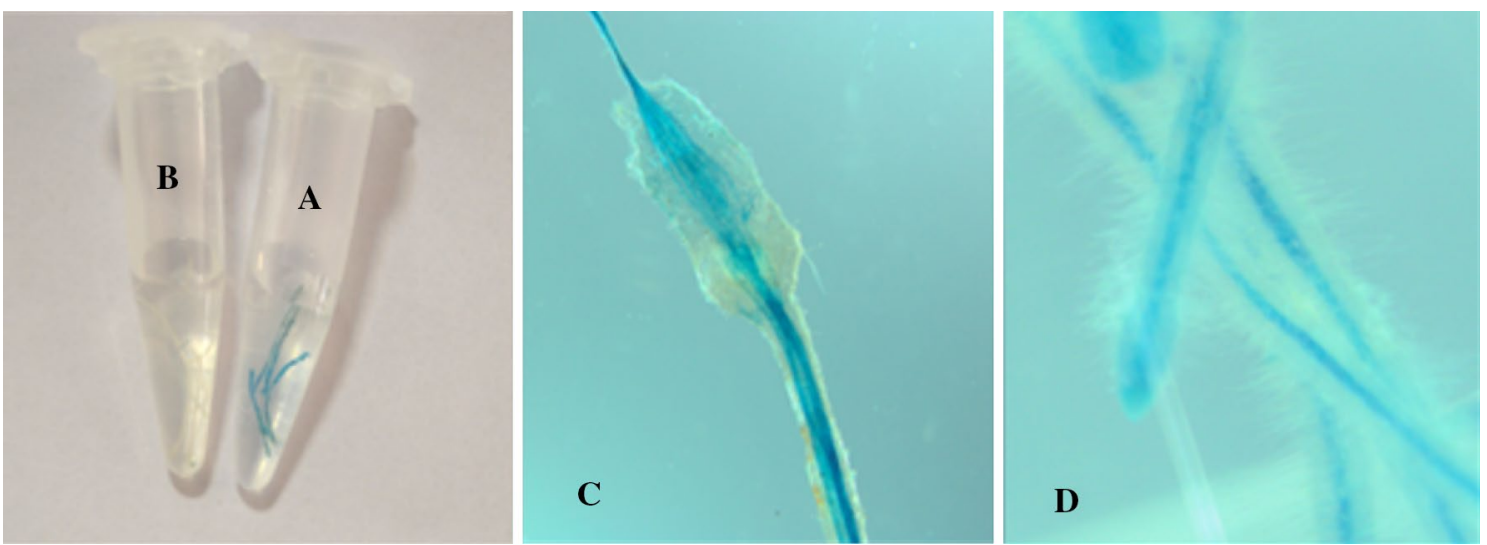

Fig. 5 GUS histochemical assay showing gene expression in transgenic roots of A. officinalis (a) while no expression can be detected in the non-transgenic root (b). Hairy root tissue transformed with the
GUS gene (c, d) and photographed under a stereomicroscope (SZX2ILLB, Japan) (a, b: $0.5 \times)(\mathbf{c}: 6 \times)(\mathbf{d}: 4 \times)$

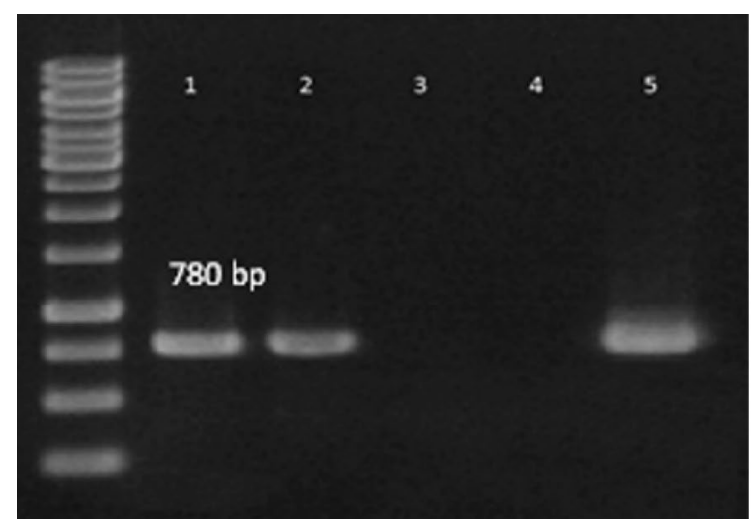

Fig. 6 Molecular analysis in transgenic hairy roots of Althaea officinalis. (Left) rolB PCR amplification: marker (1 kb ladder Fermentas); lanes $1-2$, DNA from hairy roots (780 bp); lanes 3-4, roots from a non-transformed root (negative control); lane 5, plasmid DNA (posi-

\section{Total phenolic and flavonoid contents}

The contents of phenolic and flavonoid compounds were measured in transformed hairy roots and non-transformed roots. We found substantial differences in phenolic and flavonoid contents between transformed and non-transformed roots $(p<0.01)$. The highest total phenolic content $(1.57 \pm 0.1 \mathrm{mg} / \mathrm{g})$ observed in hairy roots of A13 strain, which was 4.7 -fold more than the untransformed roots, while ATCC15834 and ATCC15834 (GUS) strains had the lowest content of phenolic and flavonoid compounds compared with the other strains. Statistical analysis for phenolic content indicated that there were significant differences among strains and control sample $(p<0.01)$. Strains A4 $(0.74 \pm 0.15 \mathrm{mg} / \mathrm{g})$ and ATCC15834 $(0.59 \pm 0.07 \mathrm{mg} / \mathrm{g})$ were not significantly different from each other (Fig. 7a). Furthermore, A4 strain showed the highest $(3.47 \pm 0.3 \mathrm{mg} / \mathrm{g}$ )

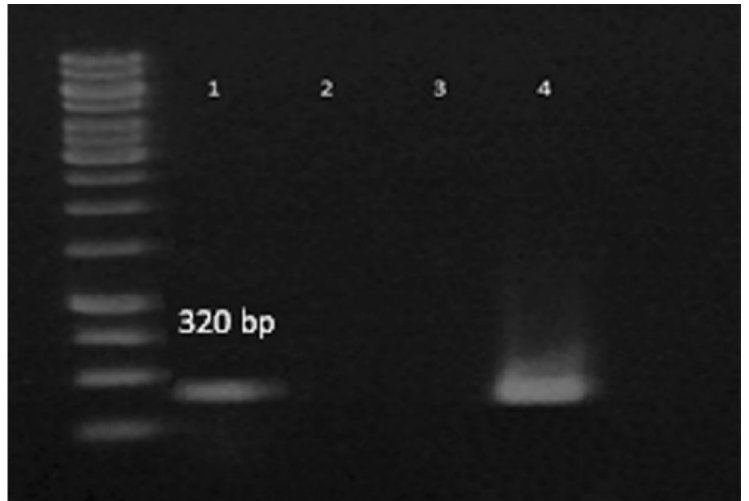

tive control). (Right) GUS PCR amplification: marker (1 kb ladder Fermentas); lanes 1, DNA from hairy roots (320 bp); lanes 2-3, roots from a non-transformed root (negative control); lane 4, plasmid DNA (positive control)

flavonoid content, which was threefold higher than control. The statistical analysis for flavonoid content showed significant differences among strains of A4 $(3.47 \mathrm{mg} / \mathrm{g})$, A13 $(2.56 \pm 0.17 \mathrm{mg} / \mathrm{g})$ and control sample $(1.15 \pm 0.2 \mathrm{mg} / \mathrm{g})$, while there were no significant differences in two strains ATCC15834 (1.65 $\pm 0.08 \mathrm{mg} / \mathrm{g})$ and ATCC15834 (GUS) $(1.71 \pm 0.12 \mathrm{mg} / \mathrm{g})$ (Fig. $7 \mathrm{~b})$. The accumulations of higher levels of phenolics and flavonoids, in hairy roots, could be due to the effect of RolB that up-regulate the genes involved in secondary metabolite production (Bulgakov et al. 2018) as reported in many other plant species (WeremczukJeżyna et al. 2013; Thiruvengadam et al. 2014; El-Esawi et al. 2017). Previously, many reports demonstrated hairy roots induced by different strains of $A$. rhizogenes vary in secondary metabolite production (Gupta et al. 2016; Thwe et al. 2016). They suggested that the secondary metabolite production is strain-specific. Similarly, Gupta et al. (2016) 

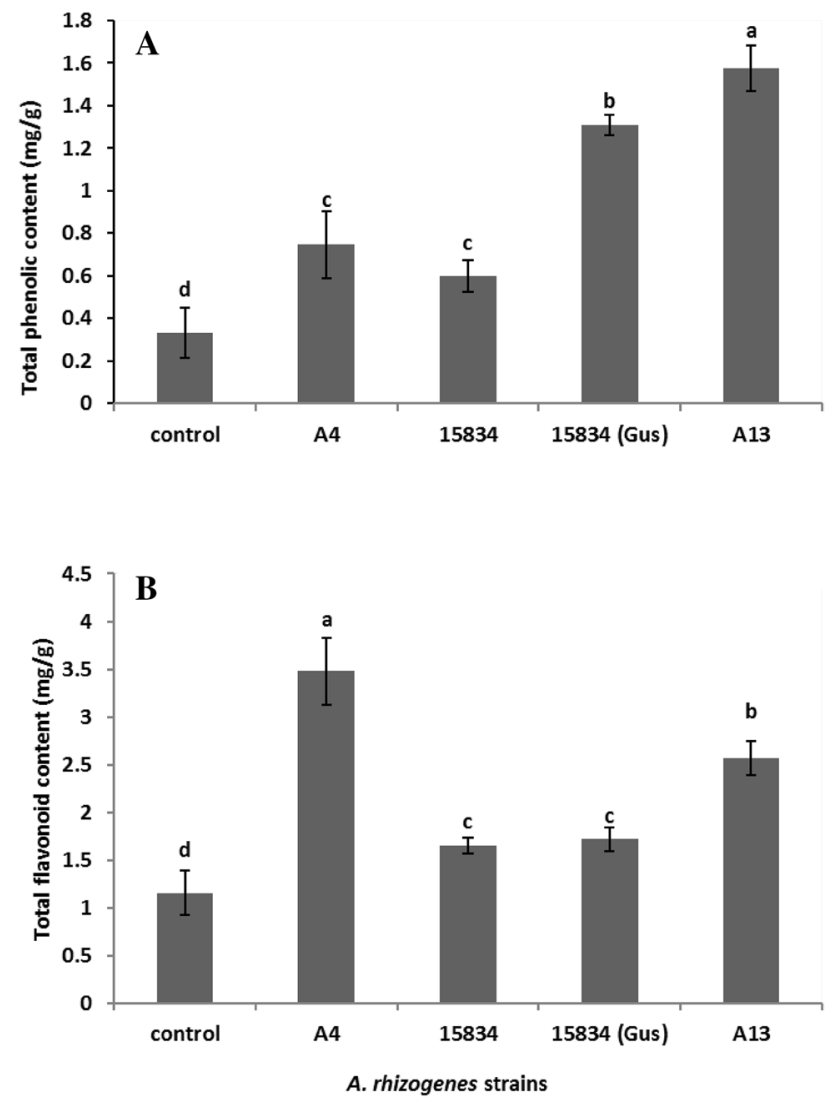

Fig. 7 Comparison of the total phenolic (a) and total flavonoid (b) content in control and hairy roots obtained by A. rhizogenes strains. Bars represent the mean $\pm \mathrm{SD}$ of three independent measurements. Different letters above columns denote statistically significant differences between groups based on the LSD test $(p<0.05)$

and Skała et al. (2015) reported that A4 was efficient for the production of secondary metabolites. Our results showed that despite the mass production of hairy roots by strain ATCC15834 $4_{(\mathrm{GUS})}$, their phenolic and flavonoid contents were not higher than the other strains. Therefore, these results suggest no correlation between regulation of growth rate and secondary metabolite synthesis in hairy roots.

\section{Conclusions}

Our results demonstrated an efficient $A$. rhizogenes-mediated transformation protocol for the foundation of A. officinalis hairy root cultures using four different $A$. rhizogenes strains: A4, A13, ATCC15834 and ATCC15834 $4_{(\mathrm{GUS})}$. Among the four different strains of A. rhizogenes, ATCC15834 ${ }_{(\mathrm{GUS})}$ had potential ability to mass production of hairy root, especially in the MS liquid medium. However, hairy roots generated by A. rhizogenes are a potential source for plant secondary metabolites, but production of certain metabolites at the commercial level could be the next important step.
Acknowledgements This work was financially supported by Neyshabur Branch, Islamic Azad University Neyshabur, Iran.

Author contributions PT performed experiments, analyzed data and drafted the paper; ASA designed and supervised the experiments, analyzed the data and drafted the paper.

\section{Compliance with ethical standards}

Conflict of interest The authors declare that they have no conflict of interest.

\section{References}

Benbassat N, Yoncheva K, Hadjimitova V, Hristova N, Konstantinov $S$, Lambov N (2014) Influence of the extraction solvent on antioxidant activity of Althaea officinalis L. root extracts. Cent Eur J Biol 9(2): 182-188

Bulgakov VP, Vereshchagina YV, Bulgakov DV, Veremeichik GN, Shkryl YN (2018) The rolB plant oncogene affects multiple signaling protein modules related to hormone signaling and plant defense. Sci Rep 8(1):2285

Chandran RP, Potty V (2008) Induction of hairy roots through the mediation of four strains of Agrobacterium rhizogenes on five host plants. Indian J Biotechnol 7(1):122-128

Chaudhuri KN, Ghosh B, Tepfer D, Jha S (2005) Genetic transformation of Tylophora indica with Agrobacterium rhizogenes A4: growth and tylophorine productivity in different transformed root clones. Plant Cell Rep 24(1):25-35

Colling J, Groenewald JH, Makunga NP (2010) Genetic alterations for increased coumarin production lead to metabolic changes in the medicinally important Pelargonium sidoides DC (Geraniaceae). Metab Eng 12(6):561-572

Drake PM, de Moraes Madeira L, Szeto TH, Ma JK (2013) Transformation of Althaea officinalis L. by Agrobacterium rhizogenes for the production of transgenic roots expressing the anti-HIV microbicide cyanovirin-N. Transgenic Res 22(6):1225-1229

El-Esawi MA, Elkelish A, Elansary HO, Ali HM, Elshikh M, Witczak J, Ahmad M (2017) Genetic transformation and hairy root induction enhance the antioxidant potential of Lactuca serriola L. Oxid Med Cell Longev 2017:5604746

Elfahmi SS, Chahyadi A (2014) Optimization of genetic transformation of Artemisia аппиа L. using Agrobacterium for Artemisinin production. Pharmacogn Mag 10(Suppl 1):S176-S180

Granato D, Shahidi F, Wrolstad R, Kilmartin P, Melton LD, Hidalgo FJ, Miyashita K, van Camp J, Alasalvar C, Ismail AB, Elmore S (2018) Antioxidant activity, total phenolics and flavonoids contents: should we ban in vitro screening methods? Food chem 264:471-475

Green MR, Sambrook J (2012) Molecular cloning: a laboratory manual, vol 1. Cold Spring Harbor Laboratory Press, New York

Guerriero G, Berni R, Muñoz-Sanchez JA, Apone F, Abdel-Salam EM, Qahtan AA, Alatar AA, Cantini C, Cai G, Hausman JF, Siddiqui KS (2018) Production of Plant Secondary Metabolites: Examples, Tips and Suggestions for Biotechnologists. Genes. https:// doi.org/10.3390/genes9060309

Gupta R, Pandey P, Singh S, Singh DK, Saxena A, Luqman S, Bawankule DU, Banerjee S (2016) Advances in Boerhaavia diffusa hairy root technology: a valuable pursuit for identifying strain sensitivity and up-scaling factors to refine metabolite yield and bioactivity potentials. Protoplasma 253(4):1145-1158

Habibi P, de Sa MF, da Silva AL, Makhzoum A, da Luz Costa J, Borghetti IA, Soccol CR (2016) Efficient genetic transformation

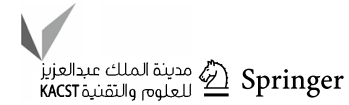


and regeneration system from hairy root of Origanum vulgare. Physiol Mol Biol Plants 22(2):271-277

Huang SH, Vishwakarma RK, Lee TT, Chan HS, Tsay HS (2014) Establishment of hairy root lines and analysis of iridoids and secoiridoids in the medicinal plant Gentiana scabra. Bot Stud 55(1):17. https://doi.org/10.1186/1999-3110-55-17

Ionkova I (1992) Alternative ways for the production of biologically active substances from Althaea officinalis var. russalka. CR Acad Bulg Sci 45:137-140

Khidyrova N, Van E, Shakhidoyatov RK, Bobakulov KM, Abdullaev N, Shakhidoyatov KM (2012) Polyprenols from leaves and stems of the plant Althaea officinalis. Chem Nat Compd 48(3):358-360

Lee SY, Kim SG, Song WS, Kim YK, Park N, Park SU (2010) Influence of different strains of Agrobacterium rhizogenes on hairy root induction and production of alizarin and purpurin in Rubia akane Nakai. Rom Biotechnol Lett 15:5405-5409

Li B, Wang B, Li H, Peng L, Ru M, Liang Z, Yan X, Zhu Y (2015) Establishment of Salvia castanea Diels $f$. tomentosa Stib. hairy root cultures and the promotion of tanshinone accumulation and gene expression with Ag, methyl jasmonate, and yeast extract elicitation. Protoplasma 253(1):87-100

Liu DH, Ren WW, Cui LJ, Zhang LD, Sun XF, Tang KX (2011) Enhanced accumulation of catharanthine and vindoline in Catharanthus roseus hairy roots by overexpression of transcriptional factor ORCA2. Afr J Biotechnol 10(17):3260

Mishra BN, Ranjan R (2008) Growth of hairy-root cultures in various bioreactors for the production of secondary metabolites. Biotechnol Appl Biochem 49(1):1-10

Moghadam YA, Piri K, Bahramnejad B, Habibi P (2013) Methyl Jasmonate and Salicylic acid effects on the dopamine production in hairy cultures of Portulaca oleracea (purslan). Bull Env Pharmacol Life Sci 2(6):89-94

Moyo M, Amoo S, Bairu M, Finnie J, Van Staden J (2008) Optimising DNA isolation for medicinal plants. S Afr J Bot 74(4):771-775

Murashige T, Skoog F (1962) A revised medium for rapid growth and bio assays with tobacco tissue cultures. Physiol Plant 15(3):473-497

Nagella P, Thiruvengadam M, Jung S, Murthy H, Chung I (2013) Establishment of Gymnema sylvestre hairy root cultures for the production of gymnemic acid. Acta Physiol Plant 35(10):3067-3073

Panda BM, Mehta UJ, Hazra S (2017) Optimizing culture conditions for establishment of hairy root culture of Semecarpus anacardium L. 3 Biotech 7(1):21. https://doi.org/10.1007/s13205-017-0608-x

Park YS, Jung ST, Kang SG, Heo BG, Arancibia-Avila P, Toledo F, Drzewiecki J, Namiesnik J, Gorinstein S (2008) Antioxidants and proteins in ethylene-treated kiwifruits. Food Chem 107(2):640-648

Pistelli L, Giovannini A, Ruffoni B, Bertoli A, Pistelli L (2010) Hairy root cultures for secondary metabolites production. In: Bio-Farms for Nutraceuticals. Springer, Boston, pp 167-184

Rahnama H, Hasanloo T, Shams MR, Sepehrifar R (2008) Silymarin production by hairy root culture of Silybum marianum (L.) Gaertn. Iran J Biotechnol 6(2):113-118

Rostampour S, Sohi HH, Jourabchi E, Ansari E (2009) Influence of Agrobacterium rhizogenes on induction of hairy roots and benzylisoquinoline alkaloids production in Persian poppy (Papaver bracteatum Lindl.): preliminary report. World J Microbiol Biotechnol 25(10):1807-1814

Runo S, Macharia S, Alakonya A, Machuka J, Sinha N, Scholes J (2012) Striga parasitizes transgenic hairy roots of Zea mays and provides a tool for studying plant-plant interactions. Plant methods 8(1):20. https://doi.org/10.1186/1746-4811-8-20

Samadi A, Jafari M, Nejhad NM, Hossenian F (2014) Podophyllotoxin and 6-methoxy podophyllotoxin Production in Hairy Root Cultures of Liunm mucronatum ssp. mucronatum. Pharmacogn Mag 10(38):154-160

Shah S, Akhtar N, Akram M, Shah PA, Saeed T, Ahmed K, Asif H (2011) Pharmacological activity of Althaea officinalis L. J Med Plants Res 5:5662-5666

Sharafi A, Sohi HH, Mirzaee H, Azadi P (2014) In vitro regeneration and Agrobacterium mediated genetic transformation of Artemisia aucheri Boiss. Physiol Mol Biol Plants 20(4):487-494

Sharifi S, Sattari TN, Zebarjadi A, Majd A, Ghasempour H (2014) The influence of Agrobacterium rhizogenes on induction of hairy roots and ss-carboline alkaloids production in Tribulus terrestris L. Physiol Mol Biol Plants 20(1):69-80

Skała E, Kicel A, Olszewska MA, Kiss AK, Wysokińska H (2015) Establishment of hairy root cultures of Rhaponticum carthamoides (Willd.) Iljin for the production of biomass and caffeic acid derivatives. Biomed Res Int. https://doi.org/10.1155/2015/181098

Sujatha G, Zdravković-Korać S, Ćalić D, Flamini G, Kumari BR (2013) High-efficiency Agrobacterium rhizogenes-mediated genetic transformation in Artemisia vulgaris: hairy root production and essential oil analysis. Ind Crops Prod 44:643-652

Tenea GN, Calin A, Gavrila L, Cucu N (2008) Manipulation of root biomass and biosynthetic potential of Glycyrrhiza glabra L. plants by Agrobacterium rhizogenes mediated transformation. Roumanian Biotechnol Lett 13(5):3922-3932

Thiruvengadam M, Praveen N, Kim EH, Kim SH, Chung IM (2014) Production of anthraquinones, phenolic compounds and biological activities from hairy root cultures of Polygonum multiflorum Thunb. Protoplasma 251(3):555-566

Thwe A, Arasu MV, Li X, Park CH, Kim SJ, Al-Dhabi NA, Park SU (2016) Effect of different Agrobacterium rhizogenes strains on hairy root induction and phenylpropanoid biosynthesis in tartary buckwheat (Fagopyrum tataricum Gaertn). Front Microbiol 7:318

Tian L (2015) Using hairy roots for production of valuable plant secondary metabolites. Adv Biochem Eng Biotechnol 149:275-324

Valimehr S, Sanjarian F, Sohi HH, Sharafi A, Sabouni F (2014) A reliable and efficient protocol for inducing genetically transformed roots in medicinal plant Nepeta pogonosperma. Physiol Mol Biol Plants 20(3):351-356

Weremczuk-Jeżyn I, Grzegorczyk-Karolak I, Frydrych B, Królicka A, Wysokińska H (2013) Hairy roots of Dracocephalum moldavica: rosmarinic acid content and antioxidant potential. Acta Physiol Plant 35(7):2095-2103

Zubricka D, Misianikova A, Henzelyova J, Valletta A, De Angelis G, D’Auria FD, Simonetti G, Pasqua G, Cellarova E (2015) Xanthones from roots, hairy roots and cell suspension cultures of selected Hypericum species and their antifungal activity against Candida albicans. Plant Cell Rep 34(11):1953-1962 